\title{
Effect of $\boldsymbol{n}$-Alkylamines on Micellization of Aqueous Sodium Dodecyl Sulphate Solutions through Ultrasonic Measurements
}

\author{
K. RAJU ${ }^{*}$, C. RAKKAPPAN ${ }^{2}$ and K. KARPAGAVALLI ${ }^{3}$ \\ ${ }^{1}$ Department of Physics, Sri Venkateswara College of Engineering, \\ Sriperumbudur-602105, India \\ ${ }^{2}$ Department of Physics (DDE), Annamalai University, Annamalai Nagar-608002, India \\ ${ }^{3}$ Department of Physics, A.V.C.College of Arts and Science, Mayiladuthurai, India \\ raju@svce.ac.in
}

Received 20 March 2013 / Accepted 30 April 2013

\begin{abstract}
Acoustical studies are undertaken in $0.025 \mathrm{~m}$ aqueous solution of SDS with the addition of $n$-alkyl amines (ethylamine, diethyl amine and triethyl amine) at various concentrations ranging from 0.01 to 0.05 molar at $303 \mathrm{~K}$. From the measured values of velocity, density, viscosity and observed absorption $\left(\alpha / \mathrm{f}^{2}\right)$ obs, various other parameters such as compressibility, free length, free volume, relative association, Rao's constant, classical absorption $\left(\alpha / \mathrm{f}^{2}\right)_{\mathrm{cl}}$, excess absorption $\left(\alpha / \mathrm{f}^{2}\right)_{\mathrm{ex}}$, volume viscosity and relaxation time are calculated and reported. The results indicate that the addition of amines to the surfactant activates the micellar growth and leads to solubilization of shorter chain amines.
\end{abstract}

Keywords: Ultrasonic velocity, Compressibility, Ultrasonic absorption, SDS, Free length

\section{Introduction}

Amphiphilic molecules like surfactants exhibit several special properties, such as critical micelle concentration (CMC), aggregation number, size and shape of the micelle and degree of micelle dissociation, because of their ability to undergo co-operative and non co-operative aggregation in aqueous system. Such properties are modified by the addition of substances such as, salts or non electrolytes (alcohols, urea, amine etc. ( $^{1-4}$, these additives can affect in many ways to delicate balance of hydrophilic and hydrophobic interactions of micelle forming surfactants.

Considerable attention has been paid in recent years to the influence of amines on ionic micellar structures, partly because they are the co-surfactants most commonly employed in the preparation of micro emulsions. In the present investigation ultrasonic method is used for obtaining dynamic information and reactions occurring in the aqueous micellar solutions $(0.025 \mathrm{~m})$ of sodium dodecyl sulphate in the presence of co-surfactant amines. The second $\mathrm{cmc}$ of SDS in water was found to be $0.025 \mathrm{~m}$, which is in agreement with the literature value $\mathrm{e}^{5}$. 


\section{Experimental}

Sodium dodecyl sulfate (SDS), $\left[\mathrm{C}_{12} \mathrm{H}_{25} \mathrm{O}_{4} \mathrm{SNa}\right] 99 \%$ and amines were obtained from Sigma and were used as received. The sample solutions containing various concentrations of $n$-alkylamines were prepared by adding 0.01 to 0.05 molar concentrations of ethylamine, diethylamine and triethylamine in $0.025 \mathrm{~m}$ aqueous solution of SDS.

The ultrasonic velocity and absorption measurements were carried out using a Pulse echo overlap technique at a fixed frequency of $10 \mathrm{MHz}$.This is a most widely used techniques for the study of ultrasonic propagation in liquids and solids. The values of density and shear viscosity of different concentrations were measured using specific gravity bottle and Ostwald's viscometer respectively. All the measurements were carried out at $303 \mathrm{~K}$ by maintaining the temperature constant by circulating water from a thermostatically controlled $\left( \pm 0.1^{\circ} \mathrm{C}\right)$ water bath.

\section{Results and Discussion}

In the present study, the ultrasonic velocity, absorption, density and viscosity measurements were carried out in $0.025 \mathrm{~m}$ aqueous solution of SDS with addition of amines (ethylamine, diethylamine and triethylamine) at different concentrations.

Employing the measured values of velocity $(U)$, density $(\rho)$ and viscosity $(\eta)$ and ultrasonic absorption, some acoustical parameters can be computed through the following expression ${ }^{6,7}$.

Adiabatic compressibility

Free length

Free volume

Rao's number

Relative association

Classical absorption

Excess absorption

Relaxation time

Volume viscosity

$$
\begin{array}{rlrl}
: & \beta_{\mathrm{ad}} & =\left[\mathrm{U}^{2} \rho\right]^{-1} \\
& : & \mathrm{L}_{\mathrm{f}} & =\mathrm{K}_{\mathrm{T}}\left[\beta_{\mathrm{ad}}\right]^{1 / 2} \\
& \mathrm{~V}_{\mathrm{f}} & =\left[\mathrm{M}_{\mathrm{eff}} \mathrm{U} / \mathrm{K} \eta\right]^{3 / 2} \\
& : & \mathrm{R} & =\mathrm{U}^{1 / 3} \mathrm{~V} \\
& \mathrm{RA} & =\left[\rho / \rho_{0}\right]\left[\mathrm{U}_{0} / \mathrm{U}\right]^{1 / 3} \\
& : & \left(\alpha / \mathrm{f}^{2}\right)_{\mathrm{cl}} & =8 \pi^{2} \eta / 3 \rho \mathrm{U}^{3} \\
& \left(\alpha / \mathrm{f}^{2}\right)_{\mathrm{ex}} & =\left(\alpha / \mathrm{f}^{2}\right)_{\mathrm{ob}}-\left(\alpha / \mathrm{f}^{2}\right)_{\mathrm{cl}} \\
: & \tau & =\beta_{0}\left[\eta_{\mathrm{v}}+(4 / 3) \eta_{\mathrm{S}}\right] \\
& : & \eta_{\mathrm{v}} & =(4 / 3) \eta_{\mathrm{s}}\left[\left(\left(\alpha / \mathrm{f}^{2}\right)_{\mathrm{ob}}-\left(\alpha / \mathrm{f}^{2}\right)_{\mathrm{cl}}\right) /\left(\alpha / \mathrm{f}^{2}\right)_{\mathrm{cl}}\right]
\end{array}
$$

Where, $\rho, V, \eta_{\mathrm{S}}, \mathrm{U}_{0}$ and $\mathrm{K}_{\mathrm{T}}$ are the density, molar volume, shear viscosity, ultrasonic velocity of water and Jacobson constant for different temperatures respectively. Then these parameters are correlated with concentration(c) and are tabulated in the Tables 1 and 2.

From the tables it is observed that ultrasonic velocity increases with increase in concentration. The adiabatic compressibility decreases with increase in concentration. A change of slope is observed between 0.03 and 0.04 molar concentration of amines. The ultrasonic absorption increases with amine concentration and a change of slope is observed above 0.03 molar concentrations.

The above changes can be explained on the basis of effect of co-surfactant on the micellar aggregate. If an additive is surface active to a hydrocarbon/water interface, it will be mainly partitioned near to the micellar palisade layer and will promote the micellar growth ${ }^{8}$. The amines have a high possibility of becoming embedded between the monomers that comprise a micelle. The presence of amine between head groups of similar charge reduces the electrostatic repulsion between the head groups, leading to a decrease in the surface area occupied per surfactant head group 9 . Thus the amine in aqueous SDS should have a tendency to form large micelles above 0.03 molar concentrations, as is indeed indicated by the observed rise in velocity and viscosity on addition of amines to $0.025 \mathrm{~m}$ SDS in micellar solutions. 
The break pronounced above $0.03 \mathrm{~m}$ concentration, is an indicative of specific interaction between the amine and the anionic surfactant head group at the micellar interface.

Table 1. Ultrasonic velocity and related parameters of n-alkylamines in the micellar solution of sodium dodecyl sulphate at $303 \mathrm{~K}$

\begin{tabular}{|c|c|c|c|c|c|c|c|c|}
\hline $\begin{array}{c}\text { Conc. } \\
\text { moles/L }\end{array}$ & $\begin{array}{c}\mathrm{U} \\
\mathrm{ms}^{-1}\end{array}$ & $\begin{array}{c}\rho \\
\mathrm{kgm}^{-3}\end{array}$ & $\begin{array}{l}\eta \times 10^{3} \\
\mathrm{Nsm}^{-2}\end{array}$ & $\begin{array}{l}\beta_{\mathrm{ad}} \times 10^{10} \\
\mathrm{~N}^{-1} \mathrm{~m}^{2}\end{array}$ & $\begin{array}{l}\mathrm{L}_{f} \\
\AA\end{array}$ & $\begin{array}{l}\mathrm{V}_{\mathrm{f}} \times 10^{8} \\
\mathrm{~m}^{3} \mathrm{~mol}^{-1}\end{array}$ & $\begin{array}{c}\mathrm{R} \\
\times 10^{3}\end{array}$ & $\begin{array}{l}\text { RA } \\
\times 10^{3}\end{array}$ \\
\hline \multicolumn{9}{|c|}{ ethylamine in $0.025 \mathrm{~m}$ aqueous solution of SDS } \\
\hline 0.01 & 1513.4 & 994.1 & 0.7752 & 4.3918 & 0.4191 & 2.3752 & 203.49 & 997.59 \\
\hline 0.02 & 14 & 94.5 & & 43 & 4187 & 2.3572 & 03.57 & 97.77 \\
\hline 0.03 & 9 & 994.7 & 55 & 05 & 4185 & 2.3334 & 03.64 & 997.85 \\
\hline 1 & 15.4 & 94 & 30 & 4.3768 & 0.4184 & 2.3201 & 03.70 & 997.92 \\
\hline 0.05 & .8 & 995.1 & 0.8140 & 4.3679 & 0.4179 & 2.2146 & 03.71 & 997.81 \\
\hline \multicolumn{9}{|c|}{ diethylamine in $0.025 \mathrm{~m}$ aqueous solution of SDS } \\
\hline 0.01 & 1506.3 & 993.8 & 0.7838 & 4.4349 & 0.4211 & 2.3205 & 203.33 & 998.76 \\
\hline 0.02 & & & & 69 & 0.4 & 2.3029 & 203.37 & 999.35 \\
\hline 0.03 & & 99 & & 4.4246 & 0.4206 & 2.3017 & 203.45 & 999.82 \\
\hline 0.04 & & 995 & & 4.4213 & 0.4205 & 2.2933 & 203.53 & 1000.10 \\
\hline 05 & & 996.9 & 0.7993 & 4.4045 & 0.4197 & 2.2649 & 65 & 1001.2 \\
\hline \multicolumn{9}{|c|}{ triethylamine in $0.025 \mathrm{~m}$ aqueous solution of SDS } \\
\hline 01 & & & & 4.4285 & 0.4208 & 2.3508 & 203.55 & 998.75 \\
\hline & & 99 & & 4.4 & & 2.2796 & 03.53 & 999.37 \\
\hline & & 993. & & 4.4 & 0.4200 & 2.2608 & 203.64 & 999.89 \\
\hline & & 996 & & 4.4 & & 2.2317 & 203.79 & 1000.30 \\
\hline 0.05 & 1510.2 & 996.5 & 0.8124 & 4.4000 & 0.4195 & 2.2162 & 203.96 & 1000.62 \\
\hline
\end{tabular}

Table 2. Ultrasonic absorption and related parameters of $n$-alkylamines in the micellar solution of sodium dodecyl sulphate at $303 \mathrm{~K}$

\begin{tabular}{|c|c|c|c|c|c|}
\hline $\begin{array}{c}\text { Conc. } \\
\text { moles/ L. }\end{array}$ & $\left(\alpha / \mathrm{f}^{2}\right)_{\mathrm{ob}}$ & $\begin{array}{c}\times 10^{15} \mathrm{Npm}^{-1} \mathrm{~s}^{2} \\
\left(\alpha / \mathrm{f}^{2}\right)_{\text {class }}\end{array}$ & $\left(\alpha / f^{2}\right)_{\mathrm{exc}}$ & $\begin{array}{l}\eta_{\mathrm{v}} \times 10^{2} \\
\mathrm{Nsm}^{-2}\end{array}$ & $\begin{array}{c}\tau \times 10^{11} \\
\sec \end{array}$ \\
\hline \multicolumn{6}{|c|}{ ethylamine in $0.025 \mathrm{~m}$ aqueous solution of SDS } \\
\hline 0.01 & 23.884 & 5.914 & 17.969 & 3.139 & 1.840 \\
\hline 0.02 & 24.861 & 5.935 & 18.925 & 3.314 & 1.920 \\
\hline 0.03 & 24.952 & 5.972 & 18.980 & 3.327 & 1.929 \\
\hline 0.04 & 25.382 & 6.021 & 19.360 & 3.398 & 1.965 \\
\hline 0.05 & 26.689 & 6.175 & 20.514 & 3.604 & 2.068 \\
\hline \multicolumn{6}{|c|}{ diethylamine in $0.025 \mathrm{~m}$ aqueous solution of SDS } \\
\hline 0.01 & 25.987 & 6.067 & 19.919 & 3.430 & 1.973 \\
\hline 0.02 & 26.173 & 6.089 & 20.084 & 3.466 & 1.992 \\
\hline 0.03 & 26.546 & 6.090 & 20.455 & 3.532 & 2.021 \\
\hline 0.04 & 26.706 & 6.156 & 20.550 & 3.556 & 2.038 \\
\hline 0.05 & 27.378 & 6.133 & 21.244 & 3.690 & 2.097 \\
\hline \multicolumn{6}{|c|}{ triethylamine in $0.025 \mathrm{~m}$ aqueous solution of SDS } \\
\hline 0.01 & 28.454 & 6.002 & 22.451 & 3.874 & 2.165 \\
\hline 0.02 & 29.020 & 6.113 & 22.906 & 3.965 & 2.216 \\
\hline 0.03 & 29.675 & 6.148 & 23.526 & 4.080 & 2.270 \\
\hline 0.04 & 30.279 & 6.195 & 24.083 & 4.186 & 2.321 \\
\hline 0.05 & 31.233 & 6.223 & 25.009 & 4.350 & 2.396 \\
\hline
\end{tabular}


Since, the number density of micelles is high and therefore, the distance between them is decreased with a necessary consequence that counter ions stay in the vicinity of the micellar surface and neutralize the micellar surface charge. It is also clear that in order to reduce the repulsive forces at the micellar surface, the counter ions must be bound firmly to the head group. These two interrelated factors are possibly responsible for the decrease in compressibility and free length and an increase in ultrasonic absorption.

However, it is reported earlier ${ }^{10}$ that $\mathrm{C}_{4}-\mathrm{C}_{10}$ - $n$-alkylamines are solubilized in micelles by electrostatic and hydrophobic effects with the amine group being left on the surface micelle. This dissociation into $-\mathrm{NH}_{3}{ }^{+}$and $\mathrm{CH}^{-}$may affect the electrostatic interactions with anionic SDS. Thus the amine head group has the ability to sit deeper in the SDS micelle, relieving the requirement of the surfactant tails to reach the center of micelle at a shorter alkyl chain length of additive. This supports the idea that a co-surfactant with the ability to bear a charge opposite to that of a surfactant head group is more effective in the growth of micelle. The variation in the other parameters with concentration also supports the same.

\section{References}

1. Giuseppe Calvaruso, Paolo Cavasino F, Carmelo Sbriziolo and LiriaTurco Liveri M, J Chem Soc Farad Trans., 1993, 89(9), 1373-1378; DOI:10.1039/FT9938901373

2. Yiv S, Zana R, Ulbrichtand W and Hoffmann H, J Collo Interf Sci., 1981, 80(1), 224-236x; DOI:10.1016/0021-9797(81)90178-8

3. Meizani A, Touraud D, Zrabada A, Clausse M and Kunz W, J Mol Liq., 2000, 84(3), 301-311; DOI:10.1016/S0167-7322(99)00196-8

4. Mandeep Singh Bakshi, Bull Chem Soc Japan, 1996, 69(10), 2723-2729; DOI:10.1246/bcsj.69.272

5. Roux-Desgranges G and Roux A H, J Mol Liq., 1999, 81(1), 3-24; DOI:10.1016/S0167-7322(99)00028-8

6. Ravichandran G, Srinivasa Rao A and Nambinarayanan T K, J Pure Appl Ultrason., 1992, 14, 46.

7. Verma H S and Vinod Kumar, Int J Pure Appl Chem., 2007, 2(4), 387.

8. Mukerjee P, Solution Chemistry of Surfactants, Ed., Mittal K L, Plenum Press, New York, 1979, 155.

9. Kabir-ud-Din, Kumar S, Aswal V K and Goyal P S, J Chem Soc Farad Trans., 1996, 92(13), 2413-2415; DOI:10.1039/FT9969202413

10. Yamashita T, Yano H, Harada S and Yasunaga T, J Phys Chem., 1983, 87(26), 5482-5485. 